\title{
Late Egyptian, Old English and the re-evaluation of Discernment politeness in remote cultures
}

\begin{abstract}
The term "Discernment" was originally coined back in the 1980s, where it was first used as an approximate translation of the Japanese term wakimae but later used independently in other contexts and cultures. In this paper, we re-assess its value as an analytical tool for two remote cultures and languages with a severely fragmented and limited textual heritage; Late Egyptian and Old English. In spite of their obvious differences, they have in common that their societies were strictly hierarchically ordered. Power was a fixed factor and not negotiable, and thus social movement was generally not possible. Our argumentation is based on a careful study of the Late Ramesside Letters, a corpus of personal communication written in Late Egyptian (c. 1099-1069BCE), and on a range of different constructions (directives, terms of address) in Old English. In these contexts, the concept of Discernment turns out to be a very useful analytical tool to describe the relationship dynamics in strictly hierarchical societies. It describes (linguistic) behaviour which is socially and situationally adequate and quasi mandatory, and which closely indexes the social relationship between speaker and addressee, as well as the social and linguistic context within which the exchange takes place.
\end{abstract}

Keywords: Politeness, Discernment, Late Egyptian, Old English, Late Ramesside Letters

\section{Introduction 1}

In spite of several decades of academic investigations of politeness and impoliteness, and in spite of the seeming pervasiveness and importance of polite and impolite behaviour in everyday life, these concepts have remained surprisingly elusive. It seems difficult to pinpoint exactly what we mean when we talk about politeness and impoliteness. Researchers have investigated both the ways in which these notions are discussed and negotiated by the language users themselves (a so-called first-order approach) and they have proposed precise definitions of (or rather, specific aspects of) politeness and impoliteness in order to investigate these aspects and their occurrence in everyday language use (a so-called second-order approach). The problems of identifying politeness are even bigger if different languages are compared, or, and this is what interests us in this contribution, if remote cultures are investigated. In a contrastive analysis of present-day languages, the differences may be considerable and ask for different concepts and theoretical frameworks in order to capture what is happening in the languages and cultures under comparison. It may be difficult for researchers who are intimately familiar with their

Many thanks to the reviewers of this article and to Dr Luis Unceta Gómez for their insight s and their assistance with improving this paper. Needless to say, all remaining errors are our own. 
own native language to acquire a similar grasp of an entirely different cultural situation. In the case of languages and cultures of bygone eras, the problems are exacerbated yet again because there are no native speakers that can be interviewed and the linguistic evidence that has survived from such periods is generally scarce and considerably random (Jacobs and Jucker 1995: 6-7; Kerbrat-Orecchioni 2011: 138). The researchers must make use of whatever traces from that culture have come down to us and try to make sense of the limited evidence that is available.

In this contribution, we will focus on two very different remote languages: Late Egyptian and Old English. At first sight, they may appear to be entirely different and not really comparable except for the fact that they are both relatively remote and that we have only a limited amount of textual evidence for both languages. However, in spite of the obvious differences between Late Egyptian and Old English, there is a key similarity: both these languages were used within cultures that had very strict hierarchical social systems, and every individual occupied a very precise place within that hierarchy, at the top, at the bottom, or at some other well-defined place between the extremes. This fixed hierarchical social order provides an interesting opportunity to test current understandings of Discernment politeness, and to explore further the linguistic manifestation of the subordinate/superior relationship dynamic. Discernment is vital for this analysis as within non-negotiable hierarchical cultures, subordinates had access to schemata of set linguis tic forms, which were used in communication with superiors. These forms did not so much reflect speakers' strategic decision to enhance or maintain their own or their addressee's face but rather, it reflected their awareness of the social context and the power differential between them and their addressees. Crucially, we will utilise this paper and the analysis of these remote languages to challenge current ideas surrounding so-called Discernment, offering a different theoretical perspective to the phenomenon, and, in light of this, assess its place within politeness research.

\section{Current understandings of Discernment}

The term "Discernment" was initially suggested by Hill et al. (1986) and further expanded upon by Ide (1989) in their respective analyses of Japanese honorifics. The choice of a specific honorific, they argued, is not based on a strategic intention by the speaker, but a quasi-mandatory selection of the appropriate linguistic item based on the social context of the interaction. For such quasi-mandatory linguistic behaviour, they propose the Japanese

term "wakimae", which stands for "the practice of polite behavior according to social conventions" (Ide 1989: 230). As a near-enough English translation for this Japanese term Hill et al. (1986: 348) and Ide (1989: 230) suggest the term "Discernment". Ide gives the following description:

\footnotetext{
Discernment is oriented mainly toward the wants to acknowledge the ascribed positions or roles of the participants as well as to accommodate to the prescribed norms of the formality of particular settings. The Speaker regulates his or her choice of linguistic forms so as to show his or her s ense of place. (Ide 1989: 231)
}

Thus, honorifics are not used to strategically meet the face-wants of the addressee, as suggested by Brown and Levinson (1987), but to acknowledge the status difference between the speaker and the addressee. 
Hill et al. (1986), who contrast politeness in Japanese and American English, suggest that in Japanese politeness the most important factor is Discernment, i.e. the more or less automatic selection of appropriate linguistic politeness forms, while the volition of the speaker to use certain polite forms for strategic reasons is less significant. In American English, according to their argumentation, the distribution of these two aspects is reversed. In their conceptualization, Discernment politeness in Japanese covers a considerably larger area of polite behaviour than in American English, where it is also in evidence but where volitional forms of politeness, such as Brown and Levinson's (1987) face-saving strategies, cover a larger area (see Figure 1).
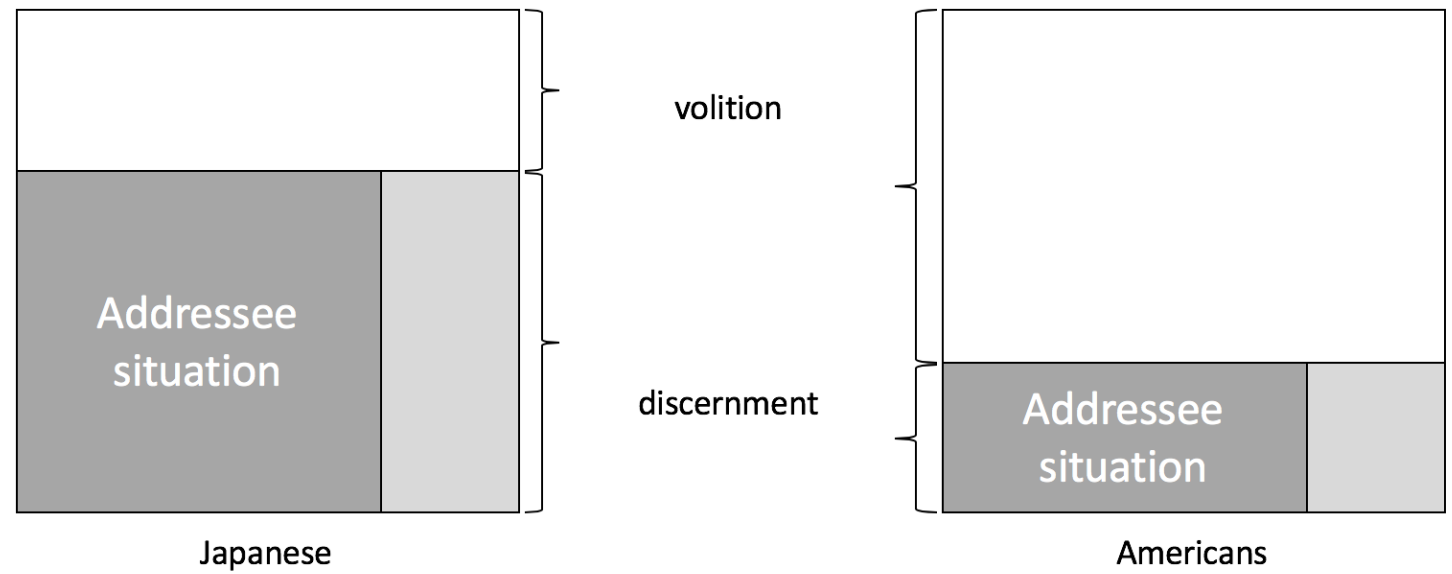

Figure 1: Scheme of strategies for linguistic politeness (based on Hill et al. 1986: 349)

The shaded areas in both squares stand for quasi-obligatory aspects of choosing the right linguistic form in a request. The smaller lightly shaded area stands for the degree of imposition exerted by a request, while the larger, darker area stands for the combination of the specific addressee and the given situation in which the request is uttered. These two aspects cover a large part of the selection process in the case of Japanese with only a small room for volitional choice by the speaker. In the case of American English, the volitional part is considerably larger, and the Discernment part accordingly reduced.

There are of course problems and strong critiques of this proposed Discernmentvolition concept, as well as attempts to re-define Discernment. Pizziconi (2003: 1499), in relation to the proposed universal politeness concept by Brown and Levinson, argues that the work by Matsumoto $(1988 ; 1989 ; 1993)$ and Ide $(1989 ; 1992)$ tried to "show that the marking of rank has a stronger regulatory power than individual volitional choices" have in Japanese language. Although some of what Pizziconi argues is now superseded by recent publications, she does make a very valid point about the universal importance of Discernment. She argues that it is not solely a particular feature of Japanese, and, as such, should not be studied in contrast to so-called "volition languages", and that defining the linguistic phenomenon in such a clear-cut dichotomy is simply not helpful:

Jary's, Meier's, and Watts' work suggests that notions of social role do have a crucial bearing on English as well, in that it is these macro-factors that constitute the background against which micro features can make a speaker's intentions (and local, contextual uses of honorific devices) interpretable at all. All their studies critically resort to notions of status differential or social distance in order to decipher a speaker's verbal behavior, even with regard to unmarked states. In other words, 
notions of status may constitute initial constrains, and where such assumptions are not shared or clear, the interlocutors must negotiate some. Sharing a set of assumptions on, or having negotiated what constitutes 'expected behaviour' (rights and duties of the participants), allows all resulting marked uses to be exploited to convey other relevant meanings. In this sense, the need of wakimae (discernment) is vital in communication regardless of the language. (Pizziconi 2003: 1500; italics original)

Pizziconi's arguments have been further developed, and, more recently, Kádár and Mills (2013: 137) highlight that the "Discernment-volition concept has been thoroughly criticised for associating non-strategic behavior with the use of honorifics". They go on to argue that the continued use of "Discernment-volition" perpetuates stereotypes and the homogenizing of cultures and languages. In their (2013: 140) reinterpretation of Discernment they build on the early work by Hill et al. and Ide, as well as the critiques of Ide's work, for example Eelen (2001: 56-57). They (2013: 141-142) argue that "wakimae" and "volition" are not parallel terms at all. The former is a term that speakers of Japanese regularly use to talk about forms of politeness in Japanese while the latter is not used in a comparable way by speakers of American English. "Volition", therefore, is a more technical term than "wakimae". It is related to a specific understanding of politeness and covers the strategic/manipulative use of politeness, which facilities the attainment of an interactional goal (Ide 1992: 298; Kádár and Mills 2013: 142). "Pairing these terms is a potential source of confusion because they represent typologically different understandings/conceptualizations of linguistic behavior" (Kádár and Mills 2013: 142).

As Haugh (2013) has argued, it is a mistake a) to think we are talking about the same phenomena across languages and cultures when in fact we are not, and b) to generate approaches or concepts which are not salient for members of cultural groups, through the as sumption of implicit worldviews that underlie the metalanguage we use. Accordingly, we regard wakimae as a Japanese-specific phenomenon and Discernment as a broader (cross-cultural/intercultural) notion. (Kádár and Mills 2013: 140)

Thus, Kádár and Mills (2013: 143) argue that we should see Discernment as a theoretical English translation of what essentially is an everyday Japanese concept describing the socially dominant norms of relationally constructive conventional and ritualistic behaviour.

Fundamentally, what Kádár and Mills highlight is the flaw, or inadequacy, in the scientific metalanguage used to categorise certain behaviour. In a later paper, Kádár and Paternoster (2015) criticise what they call an "acritical" use of the term "Discernment". They find the term problematic because it has different cultural connotations from the Japanese term "wakimae". As their data, Kádár and Paternoster use two very influential Italian conduct books first published in the sixteenth century $\mathrm{CE}$, specifically Baldasare Castiglione's Libro del cortigiano (Book of the Courtier) and Stefano Guazzo's Civil conversazione (The Civil Conversation), and they find that this creates problems for the term "Discernment" for the following two reasons:

1. the meaning and implications of discernere do, to some extent, not only differ from but contradict that of 'Discernment';

2. it is difficult even to identify discernere as the only metapragmatic 'counterpart' of 'Discernment', as this term developed within a broader metapragmatic vocabulary in $16^{\text {th }}$ century Italy. 
They support this criticism with a detailed analysis of the use not only of the metapragmatic term discernere but also semantically closely related terms in the two Italian conduct books. However, it appears that the problems can be resolved if the usual distinction between first-order concepts and second-order concepts is carefully maintained. The term "wakimae" appears to be an everyday term in Japanese to talk about specific forms of politeness. But Ide uses it - together with its rough translation equivalent "Discernment" - as a second-order concept with a relatively precise technical definition. These terms are no more than convenient labels for a carefully defined concept. Ide and her collaborators identified a certain aspect of interpersonal relationships, which they considered to be outside of the scope of the politeness strategies as described by Brown and Levinson (1987), and they decided to use the term "wakimae" or its translation equivalent "Discernment" for this specific aspect. ${ }^{2}$ In the wake of their research, other scholars found the term useful because it helped them to identify the same or very similar aspects in other cultures and other languages. In such a transfer to other situations, the term itself is, of course, always secondary. What counts is whether the two situations are sufficiently similar and in accordance with the definition proposed by Ide. This is the hallmark of a secondorder concept.

The object of investigation for Kádár and Paternoster (2015) in the two Italian conduct books, however, clearly concerns first-order concepts, i.e. the actual use of a specific set of Italian words in their socio-historical contexts as used by specific authors. First-order concepts have an etymology, which in this case goes back to Latin. They may have different shades of meanings, as Kádár and Paternoster (2015) clearly show, and they need not coincide with any second-order labels. In fact, it would be surprising if there was a complete match between first-order and second-order concepts. Second-order concepts, if they are to be useful for analytical purposes, have to be as precise as possible while firstorder concepts are, like all natural-language expressions, somewhat fuzzy, polysemous and subject to historical, social and stylistic variation.

Thus, we take the notion of "Discernment" as a second-order concept. We use it to refer to (linguistic) behaviour which is socially and situationally adequate and quasi-mandatory and which closely reflects the social relationship between speaker and addressee, as well as the social and linguistic context within which the exchange takes place. This understanding of Discernment is largely coextensive with the notion of politic behaviour (Watts). We see it as a particular form of politeness, which differs clearly from less mandatory (and, therefore, more volitional and strategic) forms of politeness. The term "politeness" itself, therefore, is much wider and covers a broader spectrum of interpersonal behaviour, which, for current purposes, does not require a precise definition because we are concerned with only a small but well-defined part of it.

Such a conceptualisation of Discernment leaves it open to an empirical investigation concerning whether Discernment was a particularly important form of politeness in any given cultural context or whether it existed at all, even though we suspect that all cultures will have at least some forms of behaviour that in a quasi-mandatory way reflect social

2 In a later paper, Ide (1992: 304, fn 1) argues that the correspondence between "wakimae" and "Discernment" is not sufficiently close. "Wakimae" is specific to Japanese and should, therefore, not be translated. 
relations between speaker and addressee. It also leaves it open as to whether a given speech community has developed a meta awareness of this specific aspect of their culture, and, as a consequence, developed a specific vocabulary (i.e. first-order labels) in order to talk about such behaviour. In the following, we are going to argue that Discernment is a useful concept to describe some pertinent aspects of behaviour in two very distinct remote cultures.

\section{Remote cultures}

Both Late Egyptian and Old English are labels for languages that were in use for many centuries and that show considerable internal variation. It is important, therefore, to be aware of the dangers of reductionist simplifications across the centuries. Obviously, these periods were not free from social, cultural and linguistic developments and generalisations across the periods always tend to be somewhat problematic.

Ancient Egyptian is one of the longest, continually attested languages in the world (in competition with Chinese) and falls into the Afro-Asiatic language family. It first appeared in writing shortly before 3000BCE and then remained active until the eleventh century $\mathrm{CE}$ (Allen 2001: 1), and is of course a dead language today, with modern Egyptians using a variety of Arabic, yet a form of Ancient Egyptian still exists within the Coptic Christian church. During its period of use, Ancient Egyptian went through five evolutionary stages: Old Egyptian, Middle Egyptian, Late Egyptian, Demotic and Coptic. It could also be written using two different writing scripts, the famous hieroglyphic and the lesser known hieratic. Within this paper, the focus of analysis is on texts written in Late Egyptian, which was used as a written form of the language between 1300-600BCE, although it was likely used as a spoken language from 1600BCE onwards (Allen 2001: 1; Junge 2005: 17-24). This is a significant period in time, covering the New Kingdom up to the Persian invasion.

The texts under review here are the Late Ramesside Letters, a corpus of over 70 personal communications written in Late Egyptian (c.1099-1069 BCE), which form one of the most complete letter collections from ancient Egypt. The letters were predominantly written during the reign of Ramesses XI, the final king of the New Kingdom, at a time when Egypt was experiencing social and economic instability. The letters document an active community based at the temple of Medinet Habu in Thebes (modern-day Luxor), with the majority of the letters written by, or sent to, Dhutmose, who was the Senior Scribe of the Necropolis (the Valley of the Kings).

The Late Ramesside Letters visibly, linguistically, and structurally demonstrate the importance of maintaining social power and position within the community under review (Ridealgh 2016). The letters follow strict patterns in communication, both in terms of grammatical forms utilised (Sweeney 2001:53), use of directives and information acts, and length of the formal introductions (Ridealgh 2013a), which change according to the relationship the sender of the letter has with the recipient. Senders of letters who are superior to the recipient tend to use a reduced formal introduction and a higher frequency of directives, whilst subordinate letter senders utilise longer formal introductions and more indirect or elaborated request acts (Ridealgh 2013a). This adherence to social hierarchy allows us to establish a pattern of linguistic expectations within this form of communication and demonstrates the fixed nature of the social power variable. It is of course not just letters that highlight the importance of a fixed social hierarchy. Ancient Egyptian tombs, temples, 
and art work utilise stylistic techniques, such as size, or quality of production materials, like granite, to demonstrate social importance. Hence, the fixed social structure was embedded and reinforced daily in writing, artwork, and architecture.

By comparison, the Anglo-Saxon period lasted from the fifth century CE well into the twelfth century. It began when Anglo-Saxon tribes who arrived from north-western Europe started to settle along the North Sea coast of Britain. For a long time, the situation was characterised by petty kingdoms, extended periods of warfare between them, and shifts of power between these kingdoms. Around the year $800 \mathrm{CE}$, the Vikings appeared on the scene who engaged the earlier Germanic settlers in long struggles for power and dominance. In the course of the ninth and tenth centuries CE, the Anglo-Saxon kingdom of Wessex extended its power and absorbed the remnants of other Anglo-Saxon kingdoms and conquered the Viking territories to the north and east, which eventually led to the kingdom of England. "Peasant communities, squeezed for their scarce resources, were the source of powerful warrior systems headed by royal dynasties" (Bartlett 2001: 52). Politically and historically, the Anglo-Saxon period came to an end with the Norman conquest of England by William the Conqueror in $1066 \mathrm{CE}$, but the culture and the language spoken by the peasant population did not change significantly for another one hundred years or so.

As pointed out above, generalisations across the entire period are problematic, but the period was clearly characterised by frequent warfare, by tribal organisations and by a strictly hierarchical structure of society in which every individual had a fixed place or rank. In fact, this rank could be given a numerical value in terms of a wergild or "man-payment". "All classes of society excepting slaves were protected by a wergild, the sum payable to their relatives to buy off the feud if they were killed" (Hough 2014: 489). The amount differed considerably according to an individual's status in society. Mercian rules for wergilds, for instance, specified a value of 120 pounds for the king. A theng was worth 1,200 shillings and a ceorl 200 shillings. These wergild values were also used as a basis for calculating specific fines for various offences. (Hough 2014: 490). In such a society, individuals were not so much appreciated as individuals but as a part of a larger whole. They derived their value, in a very real and mercantile sense, from their place in society. "It was in a sense a brutally commercial society; not only did every man have his price, and every crime its, but a man could sell himself, or his child, into slavery" (Campbell 1991: 59). In the words of Kohnen (2008b: 154):

In the tribal world of Germanic warriors, where mutual obligation and kin loyalty were prevalent, it was certainly most important to maintain friendly relationships within one's tribal network and to emphasise affectionate family relationships, but also to respect the fixed hierarchical distinctions as manifested in the difference between lord and man.

But the Anglo-Saxon world was not only a world of Germanic warriors, it was also a world that in the course of the seventh century had become Christianised. Monasteries were founded all over England and established themselves as seats of literacy and learning, and all scholarly work of the monks was carried out in Latin, while the peasant population outside of the monasteries was illiterate. The need for written Old English texts developed only gradually, and much of it appeared in a religious context. The textual evidence that has come down to us, therefore, is often a complex mixture of the Germanic and the Christian tradition (see, for instance, Gramely 2012: chapter 2; Jucker 2016: chapter 2). 


\section{Discernment politeness in Late Egyptian and Old English}

In the following, we will demonstrate how the term "Discernment politeness" applies both to Late Egyptian and to Old English. In both cases, it describes a form of behaviour that was more concerned with a recognition of one's place in a strictly hierarchical society rather than face-threat mitigation or face enhancement.

\subsection{Late Egyptian}

It is important to firmly acknowledge from the start that the ancient Egyptians had no word for politeness, and the closest word that would match the Judeo-Christian Western perception of politeness is perhaps ' $h^{c}-h m s j\left(T L A^{3}\right.$ 650008), meaning "to behave properly". However, this word only appears a limited number of times, and only in didactic texts; it does not appear in other contexts. The didactic genre is designed to express an idealised version of society, one that is resolutely based on correctly understanding related social dynamics and expected behaviour when communicating with superiors, subordinates or social equals (Ridealgh 2016). The Instructions of Ptahhotep highlights this well, revealing verbal and non-verbal expected behaviour:

If you come up against an aggressive adversary (in court),

One who has influence and is more excellent than you,

Lower your arms and bend your back,

For if you stand up to him, he will not give in to you.

You should disparage his belligerent speech

By not opposing him in his vehemence.

The result will be that he will be called boorish,

And your control of temper will have equalled his babble.

If you come up against an aggressive adversary,

Your equal, one who is of your own social standing,

You will prove yourself more upright than he by remaining silent,

While he speaks vengefully.

The deliberation by the judges will be somber,

But yourname will be vindicated in the decision of the magistrates.

If you come up against an aggressive adversary,

A man of low standing, one who is not your equal,

Do not assail him in accordance with his lowly estate.

Leave him be, and he will confound himself.

Do not answer him in order to vent your frustration.

(Simpson 2003: 131-132, maxims 2-4.)

In this extract, social hierarchy is clearly the key social factor in determining behaviour, but it also highlights important culturally embedded attitudes about how to behave in front

$T L A=$ Thesaurus Linguae Aegyptiae, the central online dictionary for Ancient Egyptian, www.aaew.bbaw.de/tla/index.html. 
of your superior. When reviewing the Late Ramesside Letters, immediate differences in linguistic behaviour are not always clear and a broader approach is required to locate and evidence instances of Discernment. Within modern research, honorifics play a fundamental role, stemming from the research by Hill et al. (1986) and Ide (1989), as discussed above in Section 2 of this paper. Yet, for Late Egyptian this is somewhat problematic. Of course, the Egyptians had a vast number of titles and honorifics for gods, the king, and the elite, which don tomb walls, funerary items such as coffins, and temples alike - all formal contexts where the status of the individual needed to be visually and metaphorically reinforced.

Yet within the Late Ramesside Letters - personal, daily communications - honorific s take very much a backseat in the communicative acts. Titles such as "Scribe of the Necropolis", "Chief Taxing Minister", and "General" are used within the address of the letters and formal introductions to help ensure that the letters reached the intended recipient. Furthermore, titles are also used in the main text as identity markers, especially for names in common use at this period, i.e. the "Gatekeeper Dhutmose" vs. the "Scribe Dhutmose". What we do find, however, is $p^{3} y=n n b$, "our lord" $/$ p $3 y=n n b$, "my lord", 5 used in reference to the highest ranked individual in the letter corpus, the General Piankh. Additionally, Piankh can also be referred to as $p 3 y=k h r y$, "your superior", ${ }^{6}$ rather than his name, marking a clear distinction between the social status of Piankh and other individuals communicating within the context of the Late Ramesside Letters. Although Piankh's name is not mentioned when "your superior" is used, all interlocutors seem to share the contextual understanding concerning who is being referred to and his social position within their relational network. The inclusion of these linguistic markers certainly highlights the use of honorifics for very superior individuals, but they are not prolifically used. On the one hand, it is clear that the Ancient Egyptians had a fixed and clear hierarchical structure, yet on the other hand, this does not seem to be manifested in honorifics in the Late Ramesside Letters, except when discussing vastly superior individuals.

Moving away from honorifics, Discernment can be viewed in other linguistic formats in letters sent by subordinates to their superiors. There are visible signs of this within the formal introductions of the letters, with subordinates utilising longer introductions to demonstrate deference - the greater the distance between the subordinate sender and the superior recipient, the longer the formal introduction (Ridealgh 2016: 248). Additionally, subordinates are less likely to utilise directives in letters to superiors, and if they do include one then it tends to take a more elaborate form in order to reduce the level of imposition. This can be seen in Example (1) below sent by Butehamun and Necropolis workmen to the General Piankh regarding the request to send Dhutmose back to Thebes (in this example Dhutmose is referred to using his alternative name Tjaroy). This type of request act is noticeably different from the directives issued by superiors, which generally consist of the imperative plus action and are only a few lexemes long.

\footnotetext{
$4 \quad$ P. BM 10375, v.11, v.15 (Černý 1939: 44-48; Wente 1967: 59-65; 1990: 194-195).

$5 \quad$ P. Geneva D 192, rt.8 (Černý 1939: 33-44; Wente 1967: 51; 1990: 185).

$6 \quad$ P. BM 10326, v.13 (Černý 1939: 17-21; Wente 1967: 37-42; 1990: 190-192).
} 


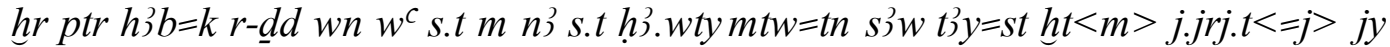
j. $n=f$ p $3 y=n n b$ tw $=n$ jry shn.w j.jrj=n dj.t gmj=k sw wih grg.tw p3 nty tw=n rh sw

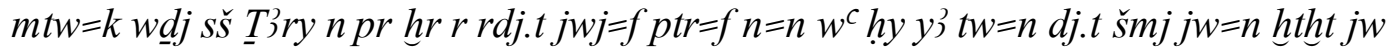
bw $r h=s n$ s.t $r d . w j=n$

'Now, see, you have sent word, saying, 'Open a place (tomb?) in the place of the ancestors, and you shall guard its seal until I have returned' so he said, our lord. We will carry out the commissions. We shall enable you to discover it — intact and prepared - in the place, which we know. And you should send the Scribe of the Necropolis Tjaroy; let him come so that he may look as an inspector for us. Oh, we tried to go but we turned back as we did not know the place to put our feet."

Subordinates are also more likely to use information acts, to confirm completion of directives made to them by superiors (superiors rarely do this), such as Example (2) taken from a letter sent by Butehamun to his father Dhutmose. In this example, the repetition of the original directive is utilised to confirm both its receipt and that the directive has been understood, before informing the recipient of the consequential action. The purpose of such communicative acts is to demonstrate the adherence to the relational norm and expectation that subordinates must complete all directives issued in order to maintain a successful relationship with their superiors.

jr p3 hỉb j.jrj=k r-dd m-jrj nnj mdw nb jnk shn.w nb n.tj $m$ sh.t n’ jt r skj [r] [dg3] [n\}] w3 $\underline{d} m-m j . t t j . n=k \underline{d j}=j[\ldots]$ nj w3 $\underline{d}$ st dg 3 nj jt bw jrj=j rwj rd.wj jm

As to the sending you made, saying "Do not neglect any commission of mine, which is in the fields, specifically to plough the grain and (to see) to the planting for me of the vegetables as well," so you said. I caused [...]. The vegetables are planted and (as for the) grain, I do not move my feet from there. ${ }^{8}$

P. BM EA $10375,{ }^{9}$ a letter sent by key necropolis officials, including Butehamun, to the General Piankh, best demonstrates the formality of the superior/subordinate relationship. The letter begins with a very extensive formal introduction, the longest in the corpus of letters, in order to demonstrate the social distance between the senders and the recipient of the letter. The concluding line of the formal introduction differs slightly from those found between family members and close friends. Instead of the phrase $m t w=j m h \quad q n j=j j m=k$, "and that I may fill my embrace with you", or one of its variants, the phrase $m t w=n m h$ $j r . t=t n m p t r=k$, "and that we may fill our eye with the sight of you", is used. This slight alteration in the address to an individual vastly superior to the senders of the letter reaffir ms this social position, as intimacy is closely linked with social status, and, as such, it would be inconceivable to the necropolis officials to have intimate contact with their superior. This adaptation of language to fit such a distant superior/subordinate relationship is also reflected in the opening lines of the main body of text of the letter. Here, instead of the phrase $s \underline{d} m=j m d w n b j . h 3 b=k n=j h r r=w$, "I have heard every matter that you sent to me",

$7 \quad$ P. BM EA 10375, v.9-13 (Černý 1939: 47; Wente 1967: 61 \& 1990: 195; Černý, Groll \& Eyre 1978: 416, ex. 1144).

$8 \quad$ P. Geneva D 407, rt.9-12 (Wente 1967: 33-34; 1990: 187-188).

$9 \quad$ P. BMEA 10375 (Černý 1939: 44-48; Wente 1967: 59-65; 1990: 194-195). 
the phrase $s \underline{d} m=n m d w . t n b j . h 3 b n=n$ p $3 y=n n b h r=w$, "we have heard all matters that our lord has sent to us", is used. The first version of the phrase with direct reference to the speaker and the addressee ("I", "you"), which is most commonly used between superiors to their subordinates or between individuals of equal social status, is adapted to fit a more formal subordinate/superior dynamic by using more indirect ways of referring to the speaker ("we") and the addressee ("our lord") (Ridealgh 2016: 260). ${ }^{10}$

The analysis of linguistic patterns in the subordinate/superior relationship dynamic as seen within the context of the Late Ramesside Letters, demonstrates the importance of convention in communication, as well as highlighting the restricted range of linguistic, grammatical, and stylistic forms available to subordinates when communicating with superiors. ${ }^{11}$ For expectations in communication to be met, these had to be used in an appropriate manner. The subordinate/superior relationship was not negotiable, and subordinates were dependent on superiors for every aspect of their existence: food, shelter, and profession. As such, the subordinate/superior divide was deeply embedded into ancient Egyptian society, going beyond showing deference, and becoming an engrained social experience and reality. Thus, Discernment is visible when the letter writing conventions are altered to reflect the power imbalance between interlocutors. Within this context, several observations regarding Discernment in the Late Ramesside Letters can be made: 1) Discernment cannot be seen as a predominantly strategic device by subordinates and must be viewed as an embedded communication phenomenon based on convention to ensure equilibrium of subordinate/superior relationships. Hence the level of volition in the formation of communicative acts is unclear. This is in direct opposition to communication acts between socially equal individuals, where the increased range of linguistic options provides a platform for strategic language use in correspondence; 2) The relationship between Discernment and convention is fundamental; 3) Within this analysis, Discernment seems not to be limited to certain contents but rather certain relationship dynamics.

\subsection{Anglo Saxon}

Let us now turn to Old English. For the Anglo-Saxon period, it is mainly the work by Kohnen (2008a) which gives us an insight into how requests, or more generally directives,

10 The afore mentioned aspects of subordinate/superior language use present their own problems as we cannot be certain all senders of letters actually wrote the text themselves; if they did in fact seek out a professional scribe and commission the letter, we cannot assess how much of the language within the letter is changed to fit someone else's world view. To a certain extent, this point has to be recognised but would negate any research into interpersonal dynamics in the ancient world if it were to take centre stage. For those identified as professional scribes and whose hand we can certify, such as Dhutmose and Butehamun, then we may be reasonably secure in the assumption that they penned the letters themselves.

11 There is not space for further discussion here within this paper concerning the conventionalised nature and restricted range of linguistic indexes. For more detailed discussion, see Ridealgh 2013a; 2013b; 2016. 
were formulated. He looks at four different constructions and assesses them in terms of politeness. The first construction consists of a directive performative, which contains a directive speech act verb in the first person (singular or plural), an indication of the addressee of the request in object position and the requested act, as in the following example.

(3) Ic bidde eow pæt ze zymon eowra sylfra, swa eowere bec eow wissiað.

(Helsinki Corpus, Flfric, Letter to Wulfsige, 26)

'I ask you to take care of yourselves, as your books teach you.'

(Kohnen 2008a: 30)

Today, such formulations would often sound somewhat brusque and even impolite. In Old English, this was a fairly common pattern (see also Bergner 1992: 169; Kohnen 2000). In the Old English section of the Helsinki Corpus, this format is attested with a frequency of four items per 10,000 words in contrast to 0.55 items in the LOB Corpus (Kohnen 2008a: 30). It is also noteworthy that verbs which turn the directive into a tentative suggestion, such as suggest or advise, were not attested in this pattern.

The second construction includes a second person pronoun plus scealt (singular) or sculon (plural), as in the following example.

(4) Him seo halge oncwæð purh gæstes giefe, Iuliana: pu scealt furpor gen, feond moncynnes, sipfæt secgan, hwa pec sende to me. ...

(Helsinki Corpus, Juliana, 122-123)

'The holy Juliana answered him by the grace of the spirit: "Foe of mankind, still further shalt thou declare thy errand, and who sent thee to me."

(Kohnen 2008a: 33)

This construction is much less frequent than the directive performatives with 0.6 instances per 10,000 words in the Old English section of the Helsinki Corpus. The request is stated in a plain and straightforward way. It comes across as direct and authoritarian, and it is almost exclusively found in a secular or Germanic context (Kohnen 2008a: 40).

The remaining two constructions, on the other hand, are found predominantly in religious prose. They use what Kohnen calls a common-ground strategy. The first of these consists of uton 'let's' plus infinitive, and the second of neodpearf or pearf 'need' plus a second- or first-person pronoun.

(5) And utan ðurh æghwæt Godes willan wyrcan swa we geornost magan.

(Helsinki Corpus, Wulfstan, Homilies, 184)

'And let us in every way perform God's commands as carefully as we may be able to.'

(Kohnen 2008a: 36)

(6) Forpon we habbap nedpearfe pæt we ongyton pa blindnesse ure ælpeodig- nesse. (Helsinki Corpus, Blickling Homilies)

'Therefore we have need to recognise the blindness of our pilgrimage.'

(Kohnen 2008a: 39)

Kohnen (2008a: 40) notes the almost complimentary distribution of the scealt/sculon construction on the one hand and the uton and the neodpearf construction on the other. 
He observes that negative politeness, which seems to be the hallmark of Present-day English, does not seem to occur in the Old English directives that he investigated. The directive performatives, which occur across a broad range of text types, appear to pay very little heed to the face wants of the addressee, and the remaining three occur in almost complimentary distribution. In the religious sphere the guiding principle seems to be the Christian ideals of humilitas and oboedientia.

$\mathrm{He}$ is very careful to point out the limitations of his study both in terms of the number of constructions under investigation and the size of the Old English section of the Helsinki Corpus, but he concludes that "despite all the qualifications with regard to the present study, the world of Anglo-Saxon directives might after all turn out to be a world beyond politeness" (Kohnen 2008a: 42).

However, it would appear to be more plausible on the basis of his data to argue that what is at work is Discernment politeness on the one hand and what might be called politeness of humility and gentleness (cf. Jucker forthc. chapter 3). The choice of the appropriate construction did not depend on individual face wants but crucially on the relationship between the speaker (or rather writer) and his addressee. It depended on the context in which it occurred. A religious text required a different construction than a secular handbook.

In a related paper, Kohnen (2008b) investigates nominal terms of address in Old English, and in particular polite and courteous ones. And he reaches similar conclusions. Face work did not play a major role. Instead, he finds evidence on the one hand for what in this case he actually calls Discernment politeness and a usage that "simply reflects the basic structure of society" (2008b: 155) and on the other hand for the Christian ideals of humilitas and caritas. As a data base he uses the Dictionary of Old English Corpus and identifies leof 'dear one, friend', bropor 'brother' and hlaford 'lord' as the most frequent among the terms of courteous address. All three of them occur predominantly in the religious domain. The term leof sometimes occurs on its own and sometimes in combination with other terms of address, as in leof hlaford. The literal translation of the single form is 'dear one, friend' but it is often translated more formally as Sir, My Lord, or dear Sir (Kohnen 2008b: 147). The term is used in a wide variety of situations, including both the address from a subordinate to a superior and the address of a superior to a subordinate. It can be combined with intimate terms of family and friendship (leofa bearn, cild, dohtor, fader), but also with terms of authority (leof cyning, hlaford, dema, lareow) (Kohnen 2008b: 149). Thus, it primarily implies sympathy and affection without reflecting the formality or intimacy of the social relationship between the speaker and the addressee.

The address term bropor predominantly occurs in religious instruction and in saints' lives, where it is used as a term of address for the audience. It can be used not only for a male sibling but also more generally for a fellow-being or a fellow Christian, and it can be used as a term of address for a fellow member of a religious order. It is not always easy to distinguish between these different senses of the word. Kohnen (2008b: 151) concludes that "in Old English the address term brothor seems to combine the intimate, mostly affectionate bond associated with the blood relationship and the basic solidarity among human beings requested in Christianity."

The term hlaford, finally, is generally used in Bible translations or in paraphrases from the Bible to address Jesus or God or some lord in the biblical texts. In saints' lives, it is used as a term of address for the saint. Outside the religious domain, the term is regularly 
used as a term of reference for a lord, but only very rarely as a term of address. Kohnen (2008b: 154-155) concludes that the term hlaford indicated a fixed position in the social hierarchy. The use of this term was automatically triggered by the situation and the relationship between speaker and addressee. It did not reflect face concerns but rather Discernment politeness or politic behaviour in the sense of Watts (1989, 2003).

A search for Old English terms in the semantic field of courtesy and politeness corroborates these findings. The terms "courtesy" and "politeness" themselves did not exist in Old English. They were borrowed from French at a much later stage in the development of English. The Thesaurus of Old English lists the relevant terms under the general heading "Humanity, courtesy, civility", for instance, manscipe 'humanity, kindness, civility'; warnes 'prudence, circumspection, caution'; manpwarnes 'gentleness, meekness, courtesy'; wynsumnes 'pleasantness, agreeableness, delight'; swetnes 'pleasantness; kindliness, goodness' or peáw-fast 'of good manners, of well-ordered life, moral, virtuous'. These terms, as the glosses that were derived from the Anglo-Saxon Dictionary Online suggest, referred to kind, gentle, meek and pleasant behaviour. There is no suggestion of behaviour that conformed to courtly etiquette or polished manners, or that refrained from imposing on the addressee (see Jucker forthc. chapter 3).

\section{Discussion and conclusion}

Any discussion of the term "Discernment" must start from the concept itself. We use it as a scientific term to categorise certain linguistic and behavioural phenomena, and, as such, it is a second order concept. In this way, Discernment has no real correlation with the Latin origins of the word in European languages, for example the Italian term discernere. In the same manner, the concept of Discernment has also evolved beyond its initial link with wakimae, as highlighted by Kádár and Mills (2013: 140), which must be identified as a specific Japanese phenomenon. As such, Discernment must be analysed at a localised level. Discussions above in regards to Late Egyptian and Old English demonstrate this, with each case study having to utilise different linguistic elements to analyse the phenomenon. However, what unites the study of Discernment in both these remote languages, is not a Discernment/volition comparison or honorifics, but rather relationships: Discernment is an essential tool that helps us to assess and understand the subordinate-superior relationship dynamic.

This relational aspect seems to have been forgotten in the majority of discussions on Discernment, which tend to pivot around Ide's work, clarifying or contrasting her findings. An example of this can be seen in the following statement by Kádár and Mills:

\footnotetext{
if we accept Ide's claim that Discernment is a matter of degree and it exists in every culture and language, including non-honorific-rich ones, it is logical to argue that Discernment should be interpreted as observance of whatever counts as normatively conventional, and potentially ritualistic, within a society. (Kádár \& Mills 2013: 147)
}

Here Kádár and Mills look to further develop Ide's argument that Discernment can be found in varying degrees across languages and cultures by establishing a partnership with cultural norms, in order to express a counter argument to the Discernment/Volition notion.

However, from the lens of remote languages this is somewhat problematic, as we cannot fully determine conventional behaviour. It also fails to take into account the level 
of awareness individuals had concerning what was normatively conventional (plus the texts that survive highlight behavioural norms of a specific group within that culture, generally of those who were elite and literate, and not representative of the whole cultural group). What we see in remote cultures is that interlocutors recognised the fixed power hierarchy. They established their own conventions and behavioural norms within the context of that specific relationship dynamic. Within the example of the Late Ramesside Letters, conventions existed within letter writing, such as language utilised and structure of the letters, yet these had to be adapted when social power and distance were taken into account - adaptations which may have differed in other contexts. In Old English, both the specific formulation of a request or the choice of a term of address are to a large extent triggered by the situation and the social relationship between the speaker and the addressee and their respective positions in society. Individual face wants take a clearly subordinate role if they exist at all.

In these examples, Discernment is then visible within the conventions established when subordinates communicate with superiors. However, it must be stressed that this communication need not simply be with direct superiors but seems to be predominantly with those individuals who were overarchingly superior within specific communities or relational networks. It is also important to add that these relational conventions are not based on individuals but rather formed through societal expectations. This is acknowledged by Ide (1992: 289), who stressed the societal appropriateness embedded into the concept of wakimae. Within the context of the remote languages under review here, the relational conventions selected also seem to be those deemed appropriate by wider societal expectations for that specific context.

The dichotomised pairing of Discernment and volition, and their subsequent relationship, also needs to be addressed. Ide (1992: 303) makes specific generalisations about wakimae-dominant societies versus volition-dominant societies. In the former type, as for instance in Japanese, people are taken to be members of a society while in the latter, as for instance in the United States, people are seen as individuals. She refers to Hall's (1976) distinction between high-context cultures, such as Japan, in which people share a large amount of common knowledge, and low-context cultures, where little contextual factors are taken for granted in interpersonal matters. High-context cultures leave little room for spontaneity and creativity because much linguistic behaviour is context bound. In low-context cultures, on the other hand, spontaneity and creativity have a much higher value. She concludes that "wakimae is a characteristic of a high context culture, while volition is a characteristic of low context culture" (Ide 1992: 303). This distinction is fundamentally flawed when applied to remote languages, there is simply not enough surviving textual sources or extended understanding of the society in question to make such conclusions or over generalisation.

Discernment and volition should not be seen as a binary opposition. In the words of Kádár and Mills (2013: 5):

we are not arguing that those scholars who describe Discernment-volition as a dichotomy misinterpret Ide (1989) since she uses these labels as categories to distinguish between formal forms and strategies. Ide arguably makes a cross -cultural overgeneralisation when she contrasts 'Wakimae dominant society' and 'volition dominant society' (1992: 303). Our main point here is simply that 
Ide's careful wording accentuates the recurring argument of this article that Ide's (1989) is (implicitly) a theory of Discernment

Discernment is a distinct second order concept and forms part of the overall picture of politeness between language users or within cultural groups; volition-based approaches (i.e. Facework) provide other parts of that picture. Viewing these two aspects in opposition to each other results in divides occurring in the way in which the culture is viewed and assessed, it does not, for example, allow for overlapping or the ability to utilise every resource in politeness research to assess and understand the role and character of politeness in differing cultures. This is vital for ancient languages, which due to fragmented data, we often do not have a complete understanding of their social structure. By directly opposing aspects of politeness research against one another, it places prestige on certain approaches or prioritises the review of certain aspects above others. With remote cultures and language systems, this is simply not a possible tactic for analysis, where you need to utilise a full "toolbox" of approaches. Thus, Discernment plays a vital role in understanding relationships in the remote past, but must be used alongside other approaches, in order to produce enough examples of politeness to make conclusions about the culture under review.

We take it as uncontroversial that Discernment is more than honorifics, yet it seems an over-simplification to define Discernment as a speaker passively submitting to the requirements of a social system (Hill et al. 1986: 348), or that it should be viewed generically in relation to localised convention/ritual (Kádár and Mills 2013: 154). We maintain that Discernment politeness is a very useful second order concept, which helps us to describe the relationship dynamic between subordinates and superiors. Our goal with this paper has been to highlight the value this concept has in the study and interpretation of politeness in remote languages and in cultures with a fixed power hierarchy.

\section{References}

Allen, James P., 2001. Middle Egyptian: An Introduction to the Language and Culture of Hieroglyphs. Cambridge: Cambridge University Press.

Anglo-Saxon Dictionary Online. Ed. Thomas Northcote Toller and Others. Comp. Sean Christ and Ondřej Tichý. Faculty of Arts, Charles University in Prague, http://www.bosworthtoller.com/

Bartlett, Robert, 2001. Medieval Britain \& Ireland. In: Barry Cunliffe, Robert Bartlett, John Morrill, Asa Briggs and Joanna Bourke (eds.). The Penguin Illustrated History of Britain \& Ireland. London: Penguin Books, 52-111.

Bergner, Heinz, 1992. The pragmatics of medieval texts. In: Dieter Stein (ed.). Cooperating with Written Texts: The Pragmatics and Comprehension of Written Texts. Berlin: Mouton de Gruyter, 163-177.

Brown, Penelope, and Stephen C. Levinson, 1987. Politeness. Some Universals in Language Usage. (Studies in Interactional Sociolinguistics 4). Cambridge: Cambridge University Press.

Campbell, James, 1991. The first Christian kings. In: James Campbell (ed.). The Anglo-Saxons. London: Penguin Books, 45-69.

Černý, Jaroslav, 1939. Late Ramesside Letters. Bibliotheca aegyptiaca 9. Brussels: Fondation égyptologique reine Élisabeth.

Černý, Jaroslav, Sarah Israelit-Groll and Christopher Eyre, 1984. A Late Egyptian Grammar. 3rd ed. Studia Pohl: Dissertationes scientificae de rebus orientis antiqui (series maior) 4. Rome: Editrice Pontificio Instituto Biblico. 
Eelen, Gino, 2001. A Critique of Politeness Theories. (Encounters 1). Manchester: St. Jerome.

Gramley, Stephan, 2012. The History of English. An Introduction. London: Routledge.

Haugh, Michael, 2013. Disentangling face, facework and im/politeness. Pragmática Sociocultural / Sociocultural Pragmatics 1.1, 46-73.

Hall, Edward T., 1976. Beyond Culture. Garden City, New York: Anchor Press.

Hill, Beverly, Sachiko Ide, Shoko Ikuta, Akiko Kawasaki and Tsunao Ogino, 1986. Universals of linguistic politeness: Quantitative evidence from Japanese and American English. Journal of Pragmatics 10, 347 371.

Hough, Carole. (2014) Wergild. In: Michael Lapidge, John Blair, Simon Keynes and Donal Scragg (eds.). (2014) The Blackwell Encyclopedia of Anglo-Saxon England. Oxford: Blackwell, 489-490.

Ide, Sachiko, 1989. Formal forms and Discernment: two neglected aspects of linguistic politeness. Multilingua 8.2/3, 223-248.

Ide, Sachiko, 1992. On the notion of "wakimae": Toward an integrated framework of linguistic politeness. In: Michiko Takeuchi (ed.). Kotoba no mozaiku. Collection of Papers in Honor of Professor Natsuko Okuda. Tokyo: Mejiro Linguistic Society, 298-305.

Jacobs, Andreas, and Andreas H. Jucker, 1995. The historical perspective in pragmatics. In: Andreas H. Jucker (ed.). Historical Pragmatics. Pragmatic Developments in the History of English. (Pragmatics \& Beyond New Series 35). Amsterdam/Philadelphia: John Benjamins, 3-33.

Jucker, Andreas H., 2016. History of English and English Historical Linguistics. (UNI WISSEN Anglistik/Amerikanistik). Stuttgart: Ernst Klett.

Jucker, Andreas H., forthc. Politeness in the History of English. From the Middle Ages to the Present Day. Cambridge: Cambridge University Press.

Junge, Friedrich, 2005. Late Egyptian Grammar: An Introduction. Translated by David Warburton. 2nd ed. Griffith Institute Publications. Oxford: The Griffith Institute.

Kádár, Dániel Z., and Sara Mills, 2013. Rethinking Discernment. Journal of Politeness Research 9.2, 133 158.

Kádár, Dániel Z., and Annick Paternoster, 2015. Historicity in metapragmatics: A study on "Discernment" in Italian metadiscourse. Pragmatics 25.3, 369-391.

Kerbrat-Orecchioni, Catherine, 2011. From good manners to facework: Politeness variations and constants in France, from the classic age to today. Journal of Historical Pragmatics 12.1-2, 133-155.

Kohnen, Thomas, 2000. Explicit performatives in Old English: A corpus-based study of directives. Journal of His torical Pragmatics 1.2, 301-321.

Kohnen, Thomas, 2008a. Directives in Old English: Beyond politeness? In: Andreas H. Jucker and Irma Taavitsainen (eds.). Speech Acts in the History of English. (Pragmatics \& Beyond New Series 176). Amsterdam/Philadelphia: John Benjamins, 27-44.

Kohnen, Thomas, 2008b. Linguistic politeness in Anglo-Saxon England? A study of Old English address terms. Journal of Historical Pragmatics 9.1, 140-158.

Matsumoto, Yoshiko. 1988. Reexamination of the universality of face: politeness phenomena in Japanese. Journal of Pragmatics 12, 403-426.

Matsumoto, Yoshiko. 1989. Politeness and conversational universals: observations from Japanese. Multilingua 8, 207-221.

Matsumoto, Yoshiko. 1993. Linguistic politeness and cultural style: observations. In Clancy, P.M. (ed.) Japanese and Korean Linguistics. Vol. 2. Stanford, CA: Stanford University, 55-67.

Pizziconi, Barbara, 2003. Re-examining politeness, face and the Japanese language. Journal of Pragmatics 35, 1471-1506. 
Pizziconi, Barbara, 2007. The lexical mapping of politeness in British English and Japanese. Journal of Politeness Research 3, 207-241.

Ridealgh, Kim, 2013a. Yes Sir! An Analysis of the Superior/Subordinate Relationship in the Late Ramesside Letters. Lingua Aegyptia: Journal of Egyptian Language Studies 21, 181-206.

Ridealgh, K. 2013b. "You Do Not Listen to Me! Facework and the Position of 'Senior' Scribe of the Necropolis?". Journal of Ancient Civilization 28: 22-40.

Ridealgh, Kim, 2016. Polite like an Egyptian? Case studies of politeness in the Late Ramesside Letters. Journal of Politeness Research 12.2, 245-266.

Simpson, Willian Kelly, 2003. The Literature of Ancient Egypt: An Anthology of Stories, Instruction and Poetry. New Haven: Yale University Press.

Sweeney, Deborah, 2001. Correspondence and Dialogue: Pragmatic Factors in Late Ramesside Letter Writing. Ägypten und Altes Testament: Studien zu Geschichte, Kultur und Religion Ägyptens und des Alten Testaments 49. Wiesbaden: Harrassowitz Verlag.

Watts, Richard J., 1989. Relevance and relational work: linguistic politeness as politic behavior. Multilingua 8.2/3, 131-166.

Watts, Richard J., 2003. Politeness (Key Topics in Sociolinguistics). Cambridge: Cambridge University Press.

Wente, Edward Frank, 1967. Late Ramesside Letters. Oriental Institute of Chicago Studies in Ancient Oriental Civilisation 33. Chicago: University of Chicago Press.

Wente, Edward Frank. 1990. Letters from Ancient Egypt, edited by E. Meltzer. Society of Biblical Literature: Writings from the Ancient World 1. Atlanta: Scholars Press. 